九州大学学術情報リポジトリ

Kyushu University Institutional Repository

\title{
Effect of Initial Moisture on the Adsorption and Desorption Equilibrium Moisture Contents of Polished Rice
}

\section{Murata, Satoshi}

Agricultural Process Engineering Laboratory, Faculty of Agriculture, Kyushu University

Amaratunga, K. S.P.

Agricultural Process Engineering Laboratory, Faculty of Agriculture, Kyushu University

Tanaka, Fumihiko

Agricultural Process Engineering Laboratory, Faculty of Agriculture, Kyushu University

Hori, Yoshiaki

Agricultural Process Engineering Laboratory, Faculty of Agriculture, Kyushu University

https://doi.org/10.5109/24048

出版情報：九州大学大学院農学研究院紀要. 38 (1/2)，pp.161-173，1993-12. Kyushu University バージョン：

権利関係 : 
J. Fac. Agr., Kyushu Univ., 38(1•2),161-173(1993)

\title{
E ffect of I nitial M oisture on the Adsorption and Desorption Equilibrium M oisture Contents of Polished R ice
}

\author{
Satoshi Murata, K.S.P. Amaratunga, F'umihiko Tanaka \\ and Yoshiaki Hori
}

Agricultural Process Engineering Laboratory, Faculty of Agriculture, Kyushu University 46-05 Fukuoka 812 Japan

(Received August 10, 2993)

\begin{abstract}
The moisture adsorption and desorption properties for polished rice have been measured using a dynamic ventilatory method. Air temperatures of $10,20,30$ and $40^{\circ} \mathrm{C}$, relative humidities of $50,60,70,80$ and $90 \%$, and five levels of initial moisture contents ranging approximately from $8 \%$ to $19 \%$ d.b. were used to obtain moisture content data. The value of equilibrium moisture content for each initial moisture content at the range of air condition was determined by a method of nonlinear least squares. Results revealed that the equilibrium moisture content depends on the initial moisture content at each temperature/r.h. condition. Observed data were fitted to the moisture transfer equation. The sorption was in the first falling rate period and the sorption coefficient $(k)$ followed the Arrhenius type temperature dependency. An attempt was made to relate the behavior of equilibrium moisture content with initial moisture content by introducing two basic parameters, the percentage deviation of equilibrium moisture content $\left(D M_{\mathrm{e}}\right)$ and the percentage deviation of initial moisture $\left(D M_{0}\right)$. Equilibrium moisture content variation due to initial moisture may be supposed as an effect of hysteresis. But the effect has to be studied further to confirm it. Increasing relative humidity tended to decrease equilibrium moisture content deviation due to initial moisture content.
\end{abstract}

\section{INTRODUCTION}

For the last two decades, the moisture adsorption phenomenon has been gaining recognition and is rapidly becoming as area of primary research in post harvest rice technology (Kunzs, 1991). However only few attempts have so far been made at the equilibrium moisture contents attained under ventilatory, non-static conditions with polished rice at different initial moisture contents. The reason is mainly that the moisture content of polished rice has less importance in storage, drying and optimum milling quality maintenance aspects in rice post harvest operations. But recent studies (Satake Co. as example) have clearly shown that the moisture content of polished rice has close relation with the eating quality of cooked rice. In other words higher moisture content rice produces good eating quality cooked rice. To maintain the quality of cooked rice, adjustment of moisture content of polished rice to a predetermined moisture level will be a requirement in the near future. To determine the way of increasing moisture under safety adsorption rates (specially preventing grain damages) needs to know the basic sorption characteristics of polished rice under different temperatures and relative humidities. Then the study of behavior of moisture in polished rice under various temperatures, relative humidities and initial moisture contents with time is an essential requirement for further studies and development of economic and efficient commercial moisture adjusters and also will contribute to the 
primary research data in post harvest rice technology.

The objectives of this study were to measure sorption characteristics of polished rice under different initial moisture content levels over a wide range of temperature and relative humidity to determine the parameters of moisture transfer equation, parameters of equilibrium relative humidity equation of Chen-Clayton and to study equilibrium moisture content variation due to initial moisture.

\section{MATERIALS AND METHODS}

Japonica rice variety of Hinohikari harvested in Fukuoka during October 1992, was used for the study. Paddy was hulled and polished to a polishing degree of $90 \%$. Approximately $2 \mathrm{~kg}$ each five samples were drawn from the bulk and the moisture contents of those were reduced to near the desired moisture contents of 8,10,14,16 and $19 \%$ d.b. by slow drying, using electrically heated low flow rate air at a temperature of not more than $30^{\circ} \mathrm{C}$. After drying all samples were placed in a $5^{\circ} \mathrm{C}$ storage until time for the tests.

A schematic diagram of the equilibration apparatus in shown in Fig. 1. Condi tioning chamber was consisting of two thermally insulated sections namely the bottom chamber and the top chamber. Bottom chamber was again divided in to a lower section and to an upper section. An electric heater was installed in the lower section and the mist produced by the ultrasonic humidifier (MITSUBISHI ELECTRIC EV-800) was sucked in to this section with some amount of surrounding air. Then the mixture of air and mist was heated up to the required temperature by the electric heater and then was pushed into the upper section of the bottom chamber by an electric fan. At this upper section temperature and relative humidity of the air were measured to control them. Temperature was controlled by a temperature controller (Chino Co., Mini-7) with the accuracy of $\pm 0.5^{\circ} \mathrm{C}$. Relative humidity was measured by a r.h. probe (VAISALA HMP115Y) and the output was fed to a pen recorder (NATIONAL PEN RECORDER MODEL VP-652A) where the position of the pen was sensed by a light sensor and then the control circuit connected to the sensor was used to control the ultrasonic humidifier. This setup was capable of maintaining $\dot{\mathrm{r}}$.h. within $\pm 1 \%$ to $2 \%$ of the desired relative humidity value depending on the temperature/r.h. combination used. The conditioned air at this section then was blown in to the top chamber by an electric centrifugal blower (SHIMADZU TYPE BLW- 30) which created suction at the air inlet. Top chamber space was mainly to get uniformity of air before passing through the samples. Conditioned air was then passed in to a thermally insulated cylinder where the samples were placed. Samples were placed in a $60 \mathrm{~mm}$ diameter $11 \mathrm{~mm}$ deep pans those having $2 \mathrm{~mm}$ mesh as the bottom. Temperature and relative humidity of air just below the samples and just above the samples were measured by $\mathrm{C}-\mathrm{C}$ thermocouples and r.h. sensors (VAISALA HMP115Y) respectively and recorded in a hybrid recorder (YOKOGAWA TYPE-UR 100 Model 4156). Flow rate of air was measured by a flow meter (LUFTHASTIGHED FLOW METER) at the outlet. The whole assembly was kept inside a temperature controlled chamber (MAEKAWAS005).

Temperature and relative humidity combinations of air used in this trial are shown in the Table 1. The velocity of flow was kept constant at $32.44(\mathrm{~m} / \mathrm{min})$ for the all 

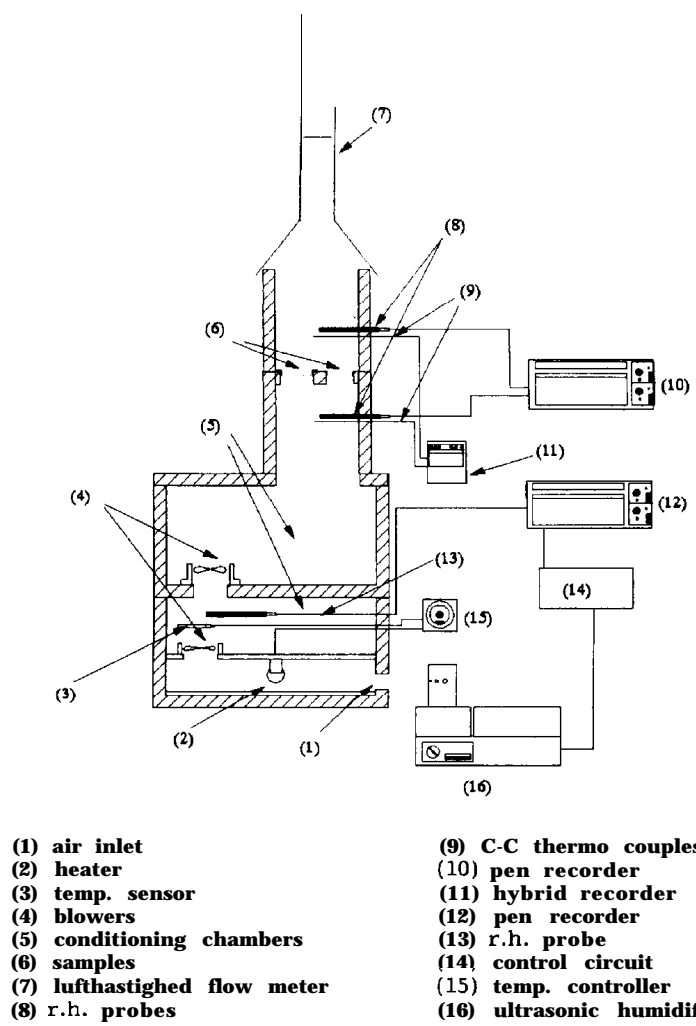
(9) C-C thermo couples
(10) pen recorder
(11) hybrid recorder
(12) pen recorder
(13) r.h. probe
(14) control circuit
(15) temp. controller
(16) ultrasonic humidifier

Fig. 1. Schematic diagram of experimental apparatus.

measurements.

All reported moisture contents are the average of two or three moisture contents calculated using $10 \mathrm{~g}$ samples by air-oven method $\left(135^{\circ} \mathrm{C}\right.$ for 24 hours).

Apparatus was first adjusted to the required temperature/relative humidity condition and was allowed at least 4 hours to get it stable. Samples of $20 \mathrm{~g}$ were measured from each initial moisture content level of polished rice and were spread on the mesh of each pan to form a thin layer to ensure uniform sorption. Weight of the samples were measured using electronic balance (METTLER PC2000) at 0,1,2,4,8,12,16,20 and 24 hours from the time the samples were inserted to the experimental apparatus for the first 24 hours and there after roughly at 12 hour intervals till 100 to 200 hours depending on the temperature/r.h. condition used. At the end of each trial the moisture contents of the samples were determined. Moisture content variation with time was calculated using the final moisture content and the weight measurements taken at each time.

Assumed that the sorption was in the first falling rate period, the following moisture transfer equation was used to fit each initial moisture content/air condition trial data.

$$
M=\left(M_{\mathrm{o}}-M_{\mathrm{e}}\right) * \exp (-k * t)+M_{\mathrm{e}}
$$


Table 1. Air conditions used to collect adsorption and desorption data for five initial moisture levels of polished rice.

\begin{tabular}{|c|c|c|c|c|c|}
\hline \multirow{2}{*}{$\begin{array}{c}\text { Temperature } \\
\left({ }^{\circ} \mathrm{C}\right)\end{array}$} & \multicolumn{5}{|c|}{ Relative humidity } \\
\hline & $50 \%$ & $60 \%$ & $70 \%$ & $80 \%$ & $90 \%$ \\
\hline $\begin{array}{l}10 \\
20\end{array}$ & $\overline{-}$ & 8 & 8 & 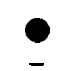 & - \\
\hline $\begin{array}{l}30 \\
40\end{array}$ & 8 & 0 & - & - & $\stackrel{\bullet}{-}$ \\
\hline
\end{tabular}

where

$M=$ moisture content at time $t, \%$ dry basis,

$M_{\mathrm{o}}=$ initial moisture content, \% dry basis,

$M_{\mathrm{e}}=$ equilibrium moisture content, $\%$ dry basis,

$t=$ time, $h$,

$k=$ sorption coefficient, $1 / h$,

The equilibrium moisture content for each experimental condition was calculated by a method of nonlinear least squares. The accuracy of the equation was expressed by the two quantitative standards, the mean relative percentage deviation $(P)$ :

$$
P=\frac{100}{N} * \Sigma \frac{\left|Y-Y^{\prime}\right|}{Y}
$$

and the standard error of the estimate value (S.E.):

$$
\text { S.E. }=\sqrt{\frac{\sum\left(Y-Y^{\prime}\right)^{2}}{d f}}
$$

where

$\mathrm{Y}=$ the measured value,

$\mathrm{Y}^{\prime}=$ the value predicted by the Equation 1,

$N=$ the number of data points,

$d f=$ degree of freedom.

The Arrhenius equation was used to express the temperature dependency of sorption coefficient $(k)$.

Arrhenius equation is:

$$
k=d * \exp (-f / T)
$$

where

$k=$ sorption coefficient of Equation $1,1 / h$,

$T=$ absolute temperature, $K$,

$d=$ parameter, $1 / h$, 
$f=$ parameter, $K$.

The estimated equilibrium moisture content values (by a method of nonlinear least squares) were used to find out constants $f_{1}, f_{2}, g_{1}$ and $g_{2}$ of the Chen-Clayton equilibrium relative humidity equation.

The Chen-Clayton equation is:

$$
h=\exp \left\{-f_{1} * T^{\mathrm{g}} * \exp \left(-f_{2} * T^{\mathrm{g}^{2}} * M_{\mathrm{e}}\right)\right\}
$$

where

$h=$ relative humidity, decimal,

$M_{\mathrm{e}}=$ moisture content, decimal dry basis,

$T=$ absolute temperature, $K$,

$f_{\mathrm{b}} f_{2} g_{\mathrm{b}} g_{2}=$ parameters.

The difference of equilibrium moisture content at each temperature/ r.h. combination due to initial moisture content was calculated as a percentage deviation from the value of equilibrium moisture content of the lowest initial moisture rice (Eq. 6). To express it graphically the above value was plotted against the percentage deviation of initial moisture from the lowest initial moisture (roughly 8\% d.b.)(Eq.7).

$$
D M_{\mathrm{e}}=\frac{M_{\mathrm{e}}-M_{\mathrm{eo}}}{M_{\mathrm{eo}}} * 100
$$

where

$D M_{\mathrm{e}}=$ percentage deviation of equilibrium moisture content,

$M_{\mathrm{e}}=$ equilibrium moisture content, \% dry basis,

$M_{\mathrm{eo}}=$ Equilibrium moisture content of the lowest initial moisture rice, \%d.b..

$$
D M_{\circ}=\frac{M_{\circ}-M_{\circ \circ}}{M_{\circ}} * 100
$$

where

$D M_{\mathrm{o}}=$ percentage deviation of initial moisture content,

$M_{0}=$ initial moisture content, $\%$ dry basis,

$M_{\mathrm{oo}}=$ the lowest initial moisture content, \% dry basis.

\section{RESULTS}

\section{Adsorption and desorption characteristics}

A set of sorption curves for the air condition of $30^{\circ} \mathrm{C}$ and $80 \%$ r.h. is shown in Fig. 2. This illustrates the effect of initial moisture content on the equilibrium moisture content. Assumed that the sorption was in the first falling rate period, the sorption coefficient $k$ of Equation 1 was calculated. Figure 3 shows the relationship of moisture ratio with time. Equilibrium moisture content calculated by a method of nonlinear least squares with initial moisture content, sorption coefficient $(k)$ of Equation 1, the standard deviation and the mean relative percentage deviation $(P)$ are listed in Table 2. 


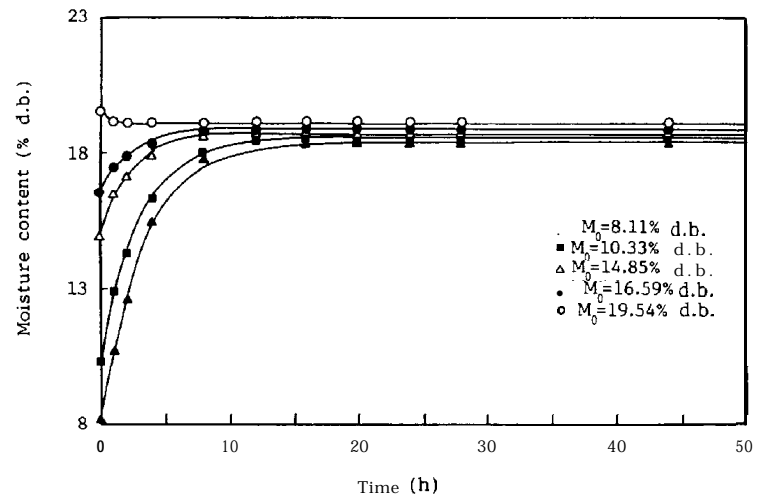

Fig. 2. Sorption curves of polished rice at air stream of $30^{\circ} \mathrm{C}$ and $80 \%$ r.h..

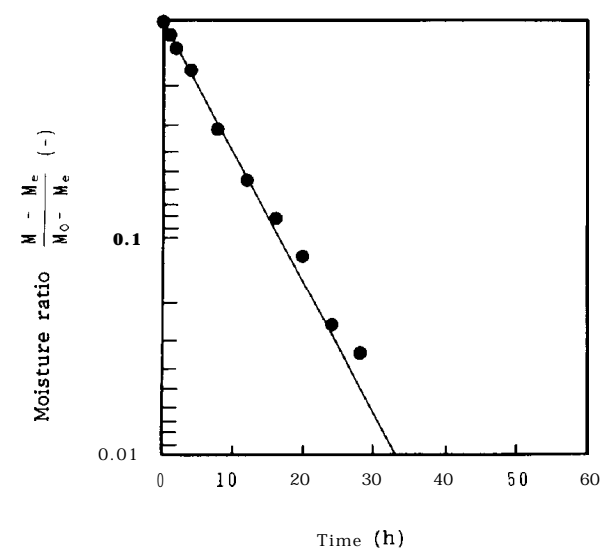

Fig. 3. Moisture ratio versus time for the $8.75 \%$ d.b. initial moisture rice at air condition of $30^{\circ} \mathrm{C}$ and $60 \%$ r.h..

The calculated values of moisture content by Equation 1 agreed well with the observed data. The desorption equilibrium moisture content was greatly differed from the adsorption equilibrium moisture under lower relative humidities $(1.12 \%$ d.b. equilibrium moisture content difference was found due to the adsorption and desorption of $10.24 \%$ d.b. and $14.90 \%$ d.b. initial moisture rice at air condition of $30^{\circ} \mathrm{C}$ and $50 \%$ r.h.). Under desorption some times the $19 \%$ d.b. initial moisture rice gave lower equilibrium moisture contents than $16 \%$ d.b. initial moisture rice (Fig. 7). This can be due to cracking of higher initial moisture rice under fast drying. Cracking will reduce the number of moisture retention sights or micro pores.

\section{Temperature dependency}

$40^{\circ} \mathrm{C}$

under $60 \%$ r.h. is shown in Fig. 4 and it clearly indicat beginning is higher under higher temperatures and at the same time the equilibrium 
Table 2. Initial moisture content $\left(\mathrm{M}_{\mathrm{o}}\right)$, sorption coefficient $(\mathrm{k})$ of Equation 1, equilibrium moisture content $\left(\mathrm{M}_{\mathrm{e}}\right)$ calculated by non-linear least squares method, standard error of the estimate and mean relative percentage deviation $(\mathrm{P})$ under each temperature/ relative humidity condition.

$T=10^{\circ} \mathrm{C}$ r.h. $=70 \%$

\begin{tabular}{rcccc}
\hline$M_{o}(\%$ d.b. $)$ & $k(-1 / \mathrm{h})$ & $M_{e}(\%$ d.b. $)$ & S.E. & $P$ \\
\hline 8.7810 & 0.0582 & 16.4212 & 0.14985 & 0.8776 \\
10.0110 & 0.0635 & 16.6958 & 0.14285 & 0.7181 \\
14.7090 & 0.0665 & 16.7606 & 0.20597 & 1.0757 \\
16.4130 & 0.0984 & 16.9789 & 0.12521 & 0.6397 \\
19.1460 & 0.4672 & 18.1062 & 0.12630 & 0.5484 \\
\hline
\end{tabular}

$T=10^{\circ} \mathrm{C}$ r.h. $=80 \%$

\begin{tabular}{rcccc}
\hline$M_{o}(\%$ d.b. $)$ & $k(-1 / \mathrm{h})$ & $M_{e}(\%$ d.b. $)$ & $S . E$. & $P$ \\
\hline 9.1620 & 0.1049 & 18.9192 & 0.31657 & 1.3830 \\
10.1240 & 0.1159 & 19.0194 & 0.21670 & 1.0016 \\
14.5480 & 0.1486 & 18.9163 & 0.16565 & 0.7201 \\
16.5500 & 0.1217 & 18.8933 & 0.14527 & 0.6472 \\
19.2610 & 0.1905 & 19.5557 & 0.04030 & 0.1388 \\
\hline
\end{tabular}

$T=20^{\circ} \mathrm{C}$ r.h. $=50 \%$

\begin{tabular}{ccccc}
\hline$M_{o}(\%$ d.b. $)$ & $k(-1 / \mathrm{h})$ & $M_{e}(\%$ d.b. $)$ & $S . E$. & $P$ \\
\hline 9.0390 & 0.0587 & 13.3504 & 0.05624 & 0.3573 \\
9.9570 & 0.0653 & 13.3707 & 0.07062 & 0.4419 \\
14.7940 & 0.9052 & 14.5200 & 0.03084 & 0.1559 \\
16.5400 & 0.3939 & 15.1457 & 0.12301 & 0.6830 \\
19.3100 & 0.6055 & 14.9076 & 0.23442 & 1.1977 \\
\hline
\end{tabular}

$T=20^{\circ} \mathrm{C}$ r.h. $=60 \%$

\begin{tabular}{rcccc}
\hline$M_{o}(\%$ d.b. $)$ & $k(-1 / \mathrm{h})$ & $M_{e}$ (\% d.b. & $S . E$. & $P$ \\
\hline 8.8140 & 0.0952 & 14.9453 & 0.06920 & 0.4354 \\
10.0040 & 0.0989 & 15.1367 & 0.06374 & 0.3503 \\
14.6700 & 0.1745 & 15.4737 & 0.03678 & 0.1646 \\
16.5990 & 0.7729 & 16.3386 & 0.02880 & 0.1635 \\
19.3210 & 0.0582 & 16.4212 & 0.14985 & 0.8776 \\
\hline
\end{tabular}


Table 2. Cont.

$T=20^{\circ} \mathrm{C}$ r.h. $=70 \%$

\begin{tabular}{rcccc}
\hline$M_{o}(\%$ d.b. $)$ & $k(-1 / \mathrm{h})$ & $M_{e}(\%$ d.b. $)$ & $S . E$. & $P$ \\
\hline 8.5780 & 0.1585 & 17.0445 & 0.09111 & 0.5234 \\
9.8820 & 0.1604 & 16.9482 & 0.08245 & 0.4055 \\
14.5380 & 0.2200 & 17.2010 & 0.11016 & 0.5357 \\
16.5400 & 0.1437 & 17.4743 & 0.09151 & 0.4462 \\
19.3210 & 0.7507 & 18.5297 & 0.06430 & 0.2817 \\
\hline
\end{tabular}

$T=30^{\circ} \mathrm{C}$ r.h. $=50 \%$

\begin{tabular}{rcccc}
\hline$M_{o}(\%$ d.b. $)$ & $k(-1 / \mathrm{h})$ & $M_{e}(\%$ d.b. $)$ & $S . E$. & $P$ \\
\hline 9.5770 & $\mathbf{0 . 0 9 5 6}$ & 12.5102 & 0.09796 & 0.6538 \\
10.2410 & 0.1055 & 12.6863 & 0.09449 & 0.6102 \\
14.9010 & 0.2652 & 13.08041 & 0.07909 & 0.4704 \\
16.6000 & 0.3956 & 13.8219 & 0.15777 & 0.8943 \\
19.1990 & 0.8354 & 13.6420 & 0.24021 & 1.2287 \\
\hline
\end{tabular}

$T=30^{\circ} \mathrm{C}$ r.h. $=60 \%$

\begin{tabular}{rcccc}
\hline$M_{o}(\%$ d.b. $)$ & $k(-1 / \mathrm{h})$ & $M_{e}(\%$ d.b. $)$ & $S . E$. & $P$ \\
\hline 8.7540 & 0.1391 & 14.0172 & 0.05925 & 0.3852 \\
10.0170 & 0.1734 & 14.0372 & 0.14492 & 0.8928 \\
14.8770 & $33.000^{*}$ & 14.9550 & 0.05590 & 0.3055 \\
16.5500 & 0.3335 & 15.4367 & 0.10255 & 0.4829 \\
19.2610 & 0.8469 & 15.2073 & 0.19946 & 0.9971
\end{tabular}

\begin{tabular}{ccccc}
$T=30^{\circ} \mathrm{C}$ r.h. $=70 \%$ & \multicolumn{5}{l}{} \\
\hline$M_{o}$ (\% d.b. $)$ & $k(-1 / \mathrm{h})$ & $M_{e}(\%$ d.b. $)$ & $S . E$. & $P$ \\
\hline 10.0580 & 0.2331 & 15.7228 & 0.05898 & 0.2851 \\
10.1800 & 0.2371 & 15.7972 & 0.08320 & 0.4014 \\
14.9430 & 0.4006 & 16.2682 & 0.06456 & 0.2992 \\
16.7640 & $-0.6332 *$ & 16.7640 & 0.05568 & 0.1730 \\
19.6780 & 0.7497 & 17.1796 & 0.13002 & 0.5579 \\
\hline
\end{tabular}


Table 2. Cont.

\begin{tabular}{ccccc}
$T=30^{\circ} \mathrm{C}$ r.h. $=80 \%$ & \multicolumn{5}{l}{} \\
\hline$M_{0}$ (\% d.b. $)$ & $k(-1 / \mathrm{h})$ & $M_{e}(\%$ d.b. $)$ & S.E. & $P$ \\
\hline 8.1080 & 0.3055 & 18.4063 & 0.13508 & 0.6614 \\
10.3320 & 0.3348 & 18.5744 & 0.08009 & 0.3407 \\
14.8500 & 0.4476 & 18.7314 & 0.09173 & 0.3011 \\
16.5920 & 0.4112 & 18.9621 & 0.06041 & 0.2237 \\
19.5430 & 1.9175 & 19.1055 & 0.02882 & 0.1254 \\
\hline & & & \\
$T=30^{\circ} \mathrm{C}$ r.h. $=90 \%$ & & & & \\
\hline \multirow{2}{*}{$(\%$ d.b. $)$} & $k(-1 / \mathrm{h})$ & $M_{e}(\%$ d.b. $)$ & \multirow{2}{*}{ S.E. } & \\
\hline \multirow{2}{*}{10.2630} & 0.5515 & 22.3900 & 0.20138 & 0.7145 \\
10.7000 & 0.5808 & 22.4502 & 0.23626 & 0.7995 \\
14.9420 & 0.7893 & 22.5518 & 0.19508 & 0.6921 \\
16.5970 & 0.8299 & 22.5422 & 0.23478 & 0.8415 \\
19.4200 & 0.8465 & 22.1409 & 0.24628 & 0.8282 \\
\hline
\end{tabular}

$T=40^{\circ} \mathrm{C}$ r.h. $=50 \%$

\begin{tabular}{rcccc}
$M_{o}(\%$ d.b. $)$ & $k(-1 / \mathrm{h})$ & $M_{e}(\%$ d.b. $)$ & $S . E$. & $P$ \\
9.6490 & 0.2225 & 11.7707 & 0.10006 & 0.6478 \\
10.0720 & 0.2453 & 11.7390 & 0.08069 & 0.5271 \\
14.7440 & 0.3952 & 12.7191 & 0.10036 & 0.6060 \\
16.4820 & 0.5812 & 12.8558 & 0.16365 & 0.9340 \\
19.5470 & 1.2020 & 13.0182 & 0.24737 & 1.4748 \\
\hline
\end{tabular}

$T=40^{\circ} \mathrm{C}$ r.h. $=60 \%$

\begin{tabular}{ccccc}
\hline$M_{o}(\%$ d.b. $)$ & $k(-1 / \mathrm{h})$ & $M_{e}(\%$ d.b. $)$ & $S . E$. & $P$ \\
\hline 8.7010 & 0.2397 & 13.0726 & 0.09915 & 0.5710 \\
9.8910 & 0.2884 & 13.0930 & 0.13379 & 0.7775 \\
14.6870 & 0.2549 & 13.9433 & 0.11280 & 0.6391 \\
16.4820 & 0.4282 & 14.2272 & 0.15434 & 0.8575 \\
19.1990 & 0.9850 & 14.0377 & 0.20820 & 1.2091 \\
\hline
\end{tabular}

$T$ : temperature,

r.h. : relative humidity

*: value is not correct due to difficulties in calculation, because the initial and the final moisture contents are much similar. 


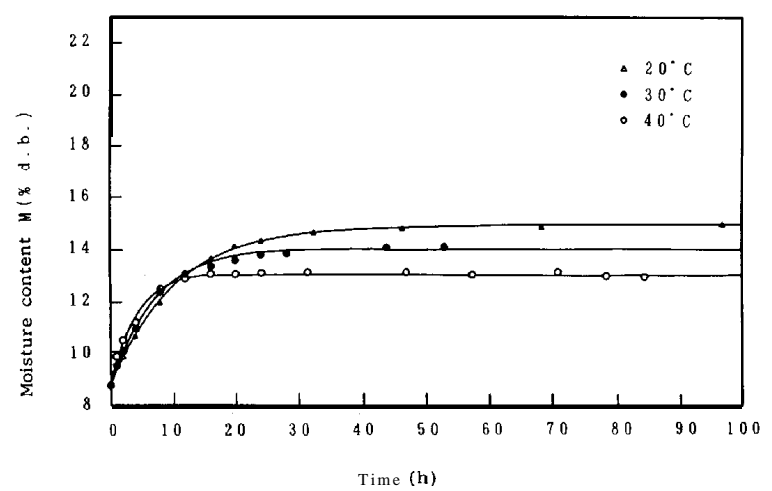

Fig. 4. Sorption curves of $8 \%$ d.b. initial moisture polished rice at $60 \%$ r.h..

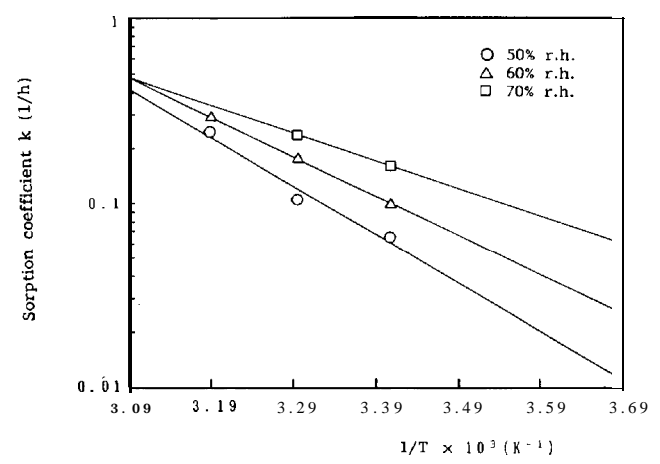

Fig. 5. Arrhenius plot for $10 \%$ d.b. initial moisture polished rice.

moisture content is low. At air condition of $40^{\circ} \mathrm{C}$ and $60 \%$ r.h., within roughly 20 hours it reached to the equilibrium moisture and at $20^{\circ} \mathrm{C} / 60 \%$ r.h., it took more than 40 hours to reach the equilibrium. Test conducted at the air condition of $10^{\circ} \mathrm{C}$ and $70 \%$ r.h. was not reached to the equilibrium within the observed time of 166 hours. So the calculated equilibrium moisture contents for the test at $10^{\circ} \mathrm{C}$ and $70 \%$ r.h. recorded in the Table 2 may be lower than the actual.

The sorption coefficient $(k)$ of Equation 1 increased with increasing temperature and followed the Arrhenius type temperature dependency. Figure 5 shows the Arrhenius plot (log $k$ versus reciprocal of absolute temperature) and the Table 3 shows the calculated parameters $(d$ and $f$ ) of the Arrhenius equation (Eq. 4) with standard error of the estimate.

\section{Sorption isotherms}

A set of adsorption isotherms calculated using Chen-Clayton equation (Eq. 5) for $10 \%$ d.b. initial moisture polished rice at 20,30 and $40^{\circ} \mathrm{C}$ with observed data is shown in Fig. 6. This shows the behavior of equilibrium moisture with temperature and relative humidity. Parameters of Chen-Clayton equation are listed in Table 4. 
Table 3. Parameters of Arrhenius equation for $10 \%$ d.b. initial moisture polished rice and the standard error of the estimate value.

\begin{tabular}{cccc}
\hline r.h. (\%) & $\mathrm{d}(1 / \mathrm{h})$ & f $(\mathrm{k})$ & S.E. \\
\hline $\mathbf{5 0}$ & $\mathbf{0 . 5 7 0 3} \times 10^{8}$ & $\mathbf{0 . 6 0 5 5} \times 10^{4}$ & $0.1626 \times 10^{-1}$ \\
60 & $0.1887 \times 10^{7}$ & $0.4914 \times 10^{4}$ & $0.9628 \times 10^{-3}$ \\
70 & $0.2246 \times 10^{5}$ & $0.3474 \times 10^{4}$ & $0.1039 \times 10^{-4}$ \\
\hline
\end{tabular}

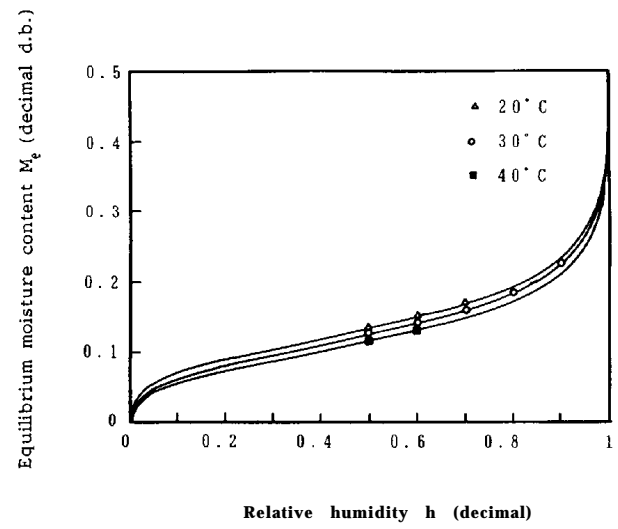

Fig. 6. Adsorption isotherms for $10 \%$ d.b. initial moisture polished rice.

Table 4. The parameters of Chen-Clayton equation for $10 \%$ d.b. initial moisture polished rice.

\begin{tabular}{cc}
\hline Parameter & value \\
\hline $\mathbf{f ~ I}$ & $2.5119274 * 10^{7}$ \\
$\mathrm{~g}_{1}$ & -2.6308339 \\
$\mathrm{f}_{2}$ & $6.0069885 * 10^{-2}$ \\
$\mathrm{~g}_{2}$ & 1.0073242 \\
\hline
\end{tabular}

\section{Hysteresis}

Figure 7 shows a set of sorption curves at air conditions of $20^{\circ} \mathrm{C}$ and $50 \%$ r.h.. $\quad$ It is clear that there is a difference of equilibrium moisture content due to initial moisture. The largest equilibrium moisture difference was found between adsorption and desorption. Figure 8 indicates the behavior of percentage deviation of equilibrium moisture content $\left(D M_{\mathrm{e}}\right.$ calculated from Eq. 6) against the percentage deviation of initial moisture $\left(D M_{\circ}\right.$ calculated from Eq. 7) for the air temperature of $30^{\circ} \mathrm{C}$. The $D M_{\circ}$ and $\boldsymbol{D}$ $M_{\mathrm{e}}$ values used to draw Fig. 8 are listed in Table 5. There was a tendency of decreasing equilibrium moisture differences due to initial moisture content with increasing relative humidity (Fig. 8). 


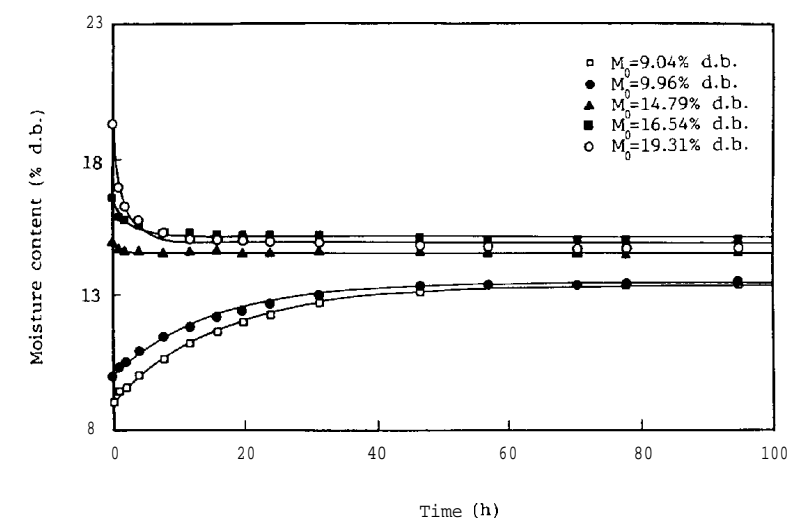

Fig. 7. Sorption curves of polished rice at air stream of $30^{\circ} \mathrm{C}$ and $50 \%$ r.h..

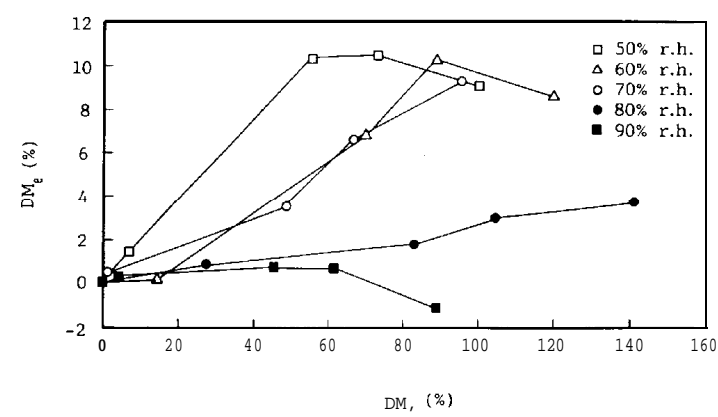

Fig. 8. Characteristics of percentage deviation of equilibrium moisture content $\left(\mathrm{DM}_{\mathrm{e}}\right)$ at $30^{\circ} \mathrm{C}$.

\section{DISCUSSION}

Sorption characteristics for polished rice subjected to adsorptive and desorptive conditions with different initial moisture contents have been presented to show the effect of initial moisture content, r.h. and temperature on the equilibrium moisture.

Results revealed that the equilibrium moisture content depends on the initial moisture content under each temperature/r.h. condition. For the measured range of air conditions, moisture transfer equation (Eq. 1) gave an excellent fit with time to observed data relating initial moisture content and equilibrium moisture. Sorption process was in the first falling rate period and the sorption coefficient $(k)$ followed the Arrhenius type temperature dependency. Variation of equilibrium moisture due to initial moisture can be supposed as an effect of hysteresis. Tendency of decreasing equilibrium moisture content difference observed with increasing relative humidity. Beyond the limits of adsorption and desorption hysteresis in grains, an extension of the theory of hysteresis is needed explaining the effect of initial moisture. This could help in understanding the status of moisture in grains and the behavior of moisture during adsorption and desorption. 
Table 5. Values of DM, and DM, calculated by Equations 6 and 7 respectively for the trials conducted at air temperature of $30^{\circ} \mathrm{C}$.

\begin{tabular}{ccc}
\hline r.h. $\%$ & $\mathrm{DM}_{\mathrm{o}}$ & $\mathrm{DM}_{\mathrm{e}}$ \\
\hline \multirow{3}{*}{50} & 0 & 0 \\
& 6.93 & 1.44 \\
& 55.59 & 10.31 \\
& 73.33 & 10.47 \\
60 & 100.47 & 9.03 \\
& 0 & 0 \\
& 14.43 & 0.14 \\
& 69.65 & 6.78 \\
70 & 89.06 & 10.21 \\
& 120.03 & 8.57 \\
& 0 & 0 \\
& 1.21 & 0.51 \\
& 48.57 & 3.50 \\
& 66.67 & 6.62 \\
& 95.65 & 9.29 \\
& 0 & 0 \\
& 27.43 & 0.87 \\
& 83.15 & 1.74 \\
& 104.64 & 2.99 \\
& 141.03 & 3.755 \\
& 0 & 0 \\
& 4.26 & 0.27 \\
& 45.59 & 0.71 \\
& 61.72 & 0.66 \\
& 89.22 & 1.12 \\
\hline & &
\end{tabular}

\section{ACKNOWLEDGEMENTS}

Sincere thanks are due to Mr. T. Hirose and Miss K. Shibuya for technical support.

\section{REFERENCES}

Banaszek, M. M., Siebenmorgen, T. J. 1990 Adsorption Equilibrium Moisture Contents of LongGain Rough Rice. J. American Society of Agricultural Engineers., 33(1):247-252

Chen, C, C., Morey, R. V. 1989 Equilibrium Relative Humidity (ERH) Relationships for YellowDent Corn. J. American Society of Agricultural Engineers., 32 (3): 999/1006

Chen, C. S. and Clayton, J. T. 1971 The Effect of Temperature on Sorption Isotherms of Biological Materials. Transactions of ASAE., 14 (5): 927-929

Kunze, 0. R. 1991 Moisture adsorption in cereal grain technology review with emphasis on rice. J.Applied Engineering in Agriculture., 7 (6): 717-723

Rizvi, S. S. H., Santos and Nigogosyan, N. 1984 An Accelerated Method for Adjustment of Equilibrium Moisture Content of Foods. J. Food Engineering., 3: 3-11 